\title{
Eritemas figurados
}

Figurate erythema

\section{Ana Paula Giraldo', Andrea Arango ${ }^{2}$}

1. Médica, Residente de Dermatología, Universidad CES, Medellín, Colombia

2. Dermatóloga, Universidad CES

\section{Resumen}

Son muchas las enfermedades de la piel que adoptan patrones clínicos diversos, como configuración anular, circular, policíclica y arqueada, entre otras. Muchas de estas lesiones se han agrupado precisamente por esta morfología dentro del grupo de los eritemas figurados; es importante, entonces, tenerlas presentes al momento de observar un patrón distintivo de distribución clínica, para hacer un diagnóstico y prescribir un tratamiento adecuado y oportuno; además, en algunos casos, se deben sospechar causas orgánicas de base que desencadenan este tipo de lesiones reactivas, algunas de las cuales pueden llegar a tener un mal pronóstico.

En este artículo se revisan los principales eritemas figurados, entre ellos, el eritema anular centrífugo, eritema migrans, eritema gyratum repens y eritema necrolítico migratorio.

PALABRAS CLAVE: eritema figurado, eritema anular centrífugo, eritema gyratum repens, eritema migrans, eritema necrolítico migratorio.

\section{Summary}

There are many skin diseases that adopt different clinical patterns such as annular, circinate, arcuate, and polycyclic configurations among others. Actually many of them have been grouped by this morphology within the group of figurate erythemas; hereby it is important to have them present when observing a distinctive clinical pattern distribution, to make a diagnosis and to prescribe an appropriate treatment, besides, in some cases, to suspect organic causes that might trigger this type of reactive lesions, some of which can have a poor prognosis.

In this article, the main figurate erythemas will be reviewed, including erythema annulare centrifugum, erythema gyratum repens, erythema migrans and necrolytic migratory erythema.

KEY WORDS: Figurate erythema, erythema annulare centrifugum, erythema gyratum repens, erythema migrans, necrolytic migratory erythema.

\section{Correspondencia:}

Ana Paula Giraldo

Email:

paula88_2@hotmail.com

Recibido 12 de mayo de 2014. Aceptado: 25 de julio de 2014.

No se reportan conflictos de interés.

\section{Introducción}

Los eritemas figurados incluyen una variedad de dermatosis caracterizadas por presentar lesiones de tipo pá- pulas y placas que se agrupan para formar un patrón, bien sea anular, circular, arqueado o policíclico. En la actualidad, la clasificación de estas entidades continúa siendo controversial y en la literatura científica siguen 
presentándose inconsistencias y contradicciones sobre su verdadera etiología ${ }^{1}$. Como lo mencionan Martinón Torres, et al., “[...] Bajo esta denominación se engloban múltiples entidades nosológicas, cuya terminología y conceptos son poco definidos, solapados y difusos, lo que dificulta su sospecha y reconocimiento clínicos[...]"2. Incluso en muchas ocasiones, otras enfermedades dermatológicas se expresan como lesiones figuradas, entre ellas, la urticaria, el eritema multiforme, la tinea corporis, el granuloma anular, la dermatitis seborreica, la psoriasis, la pitiriasis rosada, la sarcoidosis y el lupus eritematoso cutáneo, que constituyen, por tanto, sus principales diagnósticos diferenciales ${ }^{3}$.

\section{Eritema anular centrífugo}

\section{Epidemiología}

Se considera una enfermedad inflamatoria de origen desconocido y poco común, por lo cual en la actualidad son escasos los datos epidemiológicos. Sin embargo, no se han encontrado diferencias significativas en cuanto a sexo, raza o grupo etario, y aunque se dice que puede haber un pico entre la tercera y quinta décadas de la vida, también se han reportado casos de inicio en edades extremas.

Generalmente, tiene un curso crónico y recidivante, con una duración promedio de dos años, aunque hay reportes de lesiones que persisten incluso por más de 20 años $^{4}$. Se ha encontrado, además, una forma familiar de la enfermedad con herencia autosómica dominante, y se ha denominado eritema anular familiar, lo que sugiere predisposición genética ${ }^{5}$. Hay también una forma anual recurrente, que se presenta en épocas de primavera y verano; aunque su causa permanece desconocida, se cree que es una dermatosis reactiva asociada con los cambios de temperatura y la reacción a ciertos alérgenos ambientales ${ }^{1,3,6,7}$.

A lo largo de los años, el eritema anular centrífugo ha recibido diferentes nombres, como eritema gyratum perstans, eritema exudativo perstans y eritema marginatum perstans, entre muchos otros, pero fue sólo hasta 1916 cuando Jean Darier describió clínicamente la entidad con el nombre con el que actualmente se conoce ${ }^{8,9}$.

\section{Etiología}

Hay varias teorías sobre su etiología, sin embargo, hasta el momento ninguna es completamente entendida y la causa exacta permanece aún por dilucidarse. La mayoría de los autores argumentan que esta dermatosis se produce por interacciones entre las células inflamatorias, sus mediadores y sustancias que se re- conocen como antígenos extraños y que se difunden a través de la piel.

Entre los principales factores desencadenantes se postulan neoplasias como el cáncer de mama, el cáncer gástrico, las leucemias y los linfomas ${ }^{10-15}$, infecciones crónicas por molusco contagioso, Escherichia coli, virus de Epstein-Barr, dermatofitos, tuberculosis, áscaris, rickettsias y Candida ${ }^{16-23}$, fármacos como piroxicam, hidroclorotiazida, amitriptilina, sales de oro, hidroxicloroquina, espironolactona y cimetidina ${ }^{24-31}$, alimentos, trastornos autoinmunitarios, endocrinopatías, discrasias sanguíneas, embarazo y causas hormonales como la menstruación, aunque en muchos casos no se logra encontrar el factor causal ${ }^{3,4,32}$. Otras entidades que se han visto relacionadas son: enfermedad de GravesBasedow, sarcoidosis, enfermedades ampollosas, trastornos hepáticos, cirugías y estrés ${ }^{33-41}$.

Hay algunas citocinas que podrían desempeñar algún papel en la fisiopatología del eritema anular centrífugo, entre ellas el interferón (IFN), el factor de necrosis tumoral alfa (TNF- $\alpha$ ) y la interleucina 2 (IL-2). La respuesta al etanercept también apoya la hipótesis que sugiere una mediación de células Th1 con niveles elevados de TNF- $\alpha$ y su asociación con citocinas proinflamatorias; se cree que esta producción local de sustancias quimioatrayentes es la causa del aspecto migratorio de las lesiones ${ }^{3}$.

\section{Manifestaciones clínicas}

Se presentan como múltiples máculas o pápulas eritematosas asintomáticas, con crecimiento centrífugo y aclaramiento central que les dan un patrón anular. Las lesiones adyacentes tienden a confluir, volviéndose circulares, policíclicas o arqueadas, y presentan una expansión rápida, de entre 2 y $3 \mathrm{~mm}$ por día, pudiendo variar en tamaño y alcanzando en ocasiones los 10 $\mathrm{cm}$ de diámetro; tienen predilección por el tronco, los glúteos y los muslos, mientras que el cuero cabelludo, las palmas, las plantas y las mucosas suelen estar respetados $^{32}$ (FIGURAS 1 Y 2). El número de lesiones varía, aunque es usual encontrar entre 1 y 20 lesiones por paciente $e^{9,32}$.

El eritema anular centrífugo se ha clasificado en dos tipos, el superficial o clásico y el profundo. La variedad superficial, o clásica, se compone de pápulas eritematosas en patrón anular, con un borde interno sutil y descamación fina, mientras que la variedad profunda se caracteriza por una placa eritematosa en patrón anular o numular, con un borde infiltrado, urticariforme, de 3 a $10 \mathrm{~mm}$, sin descamación y con grados variables de hiperpigmentación posinflamatoria al resolverse. No obstante, aún no se sabe si esta última variedad es ciertamente un subtipo de eritema anular centrífugo o si en 


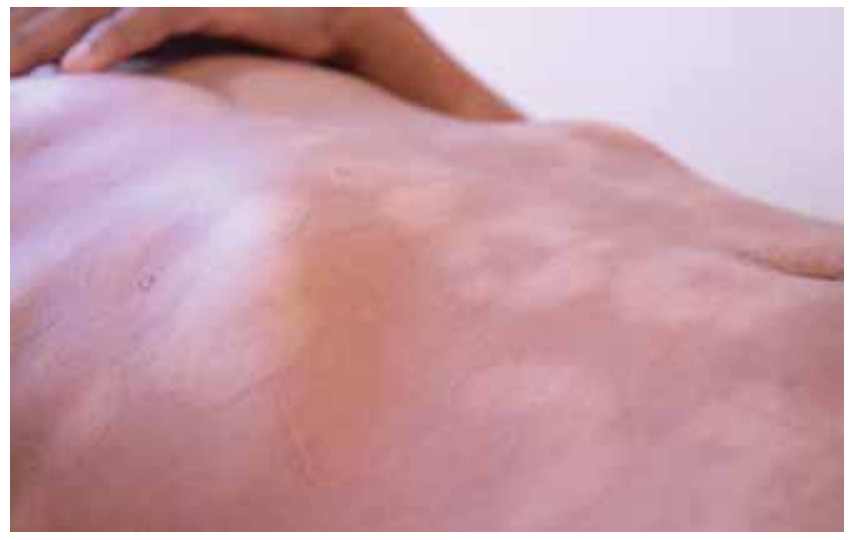

FIGURA 1. Eritema anular centrífugo superficial. Placas anulares con centro hipopigmentado y borde elevado.

realidad corresponde a una forma de lupus eritematoso cutáneo denominado lupus tumidus; por esta razón, algunos autores consideran el clásico, como la única forma de eritema anular centrífugo ${ }^{3,32}$.

Por la gran variedad de patrones morfológicos que pueden observarse, muchos autores consideran que el diagnóstico de eritema anular centrífugo es más una mezcla de varios trastornos relacionados y no una enfermedad por sí misma ${ }^{6,32}$.

\section{Histopatología}

Los hallazgos histopatológicos en las formas superficiales son inespecíficos, con un infiltrado mononuclear perivascular en la dermis superficial y media en el $100 \%$ de los pacientes, que adopta un patrón en 'manga de camisa' en algunos casos; se encuentra también espongiosis en el $80 \%$ de los casos, mientras que las paredes de los vasos y la epidermis, generalmente, se encuentran respetadas. La descamación se produce por montículos sutiles de paraqueratosis y se presenta hasta en el $66 \%{ }^{32}$. Las formas profundas, por su parte, presentan hallazgos muy similares a los del lupus tumidus, con un infiltrado inflamatorio mononuclear en la dermis profunda, espongiosis mínima o ausente y rara vez focos de paraqueratosis (3\%); cabe resaltar que hasta en $25 \%$ de los casos pueden encontrarse depósitos de mucina, y hasta en $69 \%$, presencia de melanófagos ${ }^{32}$. Los hallazgos más importantes se obtienen del borde de la lesión, por lo que es este el sitio ideal de toma de la muestra ${ }^{9,32}$.

\section{Diagnóstico diferencial}

El eritema anular centrífugo superficial debe diferenciarse de otras dermatosis (TABLA 1), ya que estas frecuentemente adoptan un patrón de distribución anular ${ }^{6}$.

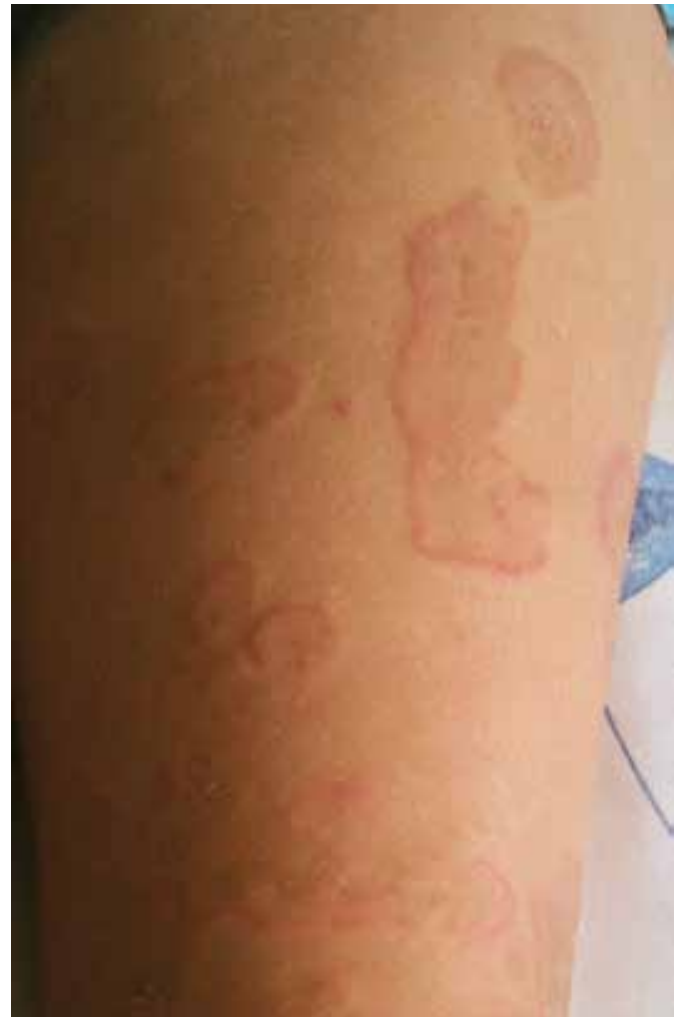

FIGURA 2. Eritema anular centrífugo. Se observan placas anulares con un borde elevado y eritematoso.

\begin{tabular}{|c|c|}
\hline Pitiriasis rosada & Dermatitis seborreica \\
\hline $\begin{array}{l}\text { Parasoriasis de pequeñas } \\
\text { placas }\end{array}$ & $\begin{array}{l}\text { Linfoma cutáneo de } \\
\text { células T }\end{array}$ \\
\hline $\begin{array}{l}\text { Pseudolinfoma (infiltrado } \\
\text { linfocítico de Jessner) }\end{array}$ & Granuloma anular \\
\hline Sarcoidosis anular & Psoriasis anular \\
\hline Urticaria anular & $\begin{array}{l}\text { Lupus eritematoso } \\
\text { discoide }\end{array}$ \\
\hline Tiña del cuerpo & Sifilis \\
\hline Lepra & $\begin{array}{l}\text { Erupción anular por } \\
\text { fármacos }\end{array}$ \\
\hline Pénfigo & Penfigoide ampollar \\
\hline
\end{tabular}

TABLA 1. Diagnósticos diferenciales de eritema anular centrífugo superficial.

Por esto, es fundamental la adecuada correlación histopatológica e, incluso, la realización de tinciones especiales como PAS, en caso de sospechar infecciones fúngicas, o estudios de inmunohistoquímica, en caso de sospechar micosis fungoide ${ }^{3,32}$.

La forma profunda debe diferenciarse de enfermedades 
como el lupus tumidus, la erupción solar polimorfa, el eritema crónico migratorio y el linfoma linfocítico. Entre estas entidades, la que más se asemeja al eritema anular centrífugo profundo es el lupus tumidus, al que en algunos reportes lo describen como la misma entidad ${ }^{32,42,43}$.

\section{Tratamiento}

Hasta la fecha no hay un tratamiento específico ni protocolos de manejo establecidos y se considera que la intervención más importante es identificar y, si es posible, retirar el factor desencadenante ${ }^{3,9}$.

Aunque, generalmente, es una entidad asintomática, en casos de prurito, los antihistamínicos pueden ser de utilidad. Se han usado esteroides tópicos de alta potencia y derivados del alquitrán de hulla, con resultados variables ${ }^{3}$. Los esteroides sistémicos se usan en casos seleccionados, ya que generalmente las lesiones reaparecen al suspenderlos ${ }^{3}$.

Hay reportes publicados de pacientes tratados con antibióticos, antifúngicos y metronidazol con buenos resultados, así como también casos graves tratados con interferón alfa, calcipotriol ${ }^{44} \mathrm{y}$ tacrolimus al $0,1 \% \%^{45}$. Más recientemente, el uso de etanercept $(25 \mathrm{mg}$ bisemanales) ha mostrado mejoría en algunos pacientes, con resolución del $95 \%$ de las lesiones después de cuatro semanas, aunque con recaídas variables ${ }^{46}$. El tiempo de tratamiento de cada agente farmacológico no se encuentra determinado en la literatura científica.

\section{Eritema gyratum repens}

El eritema gyratum repens se considera una entidad paraneoplásica, ya que en 80 a $82 \%$ de los casos se asocia con neoplasias malignas internas, principalmente cáncer de pulmón ${ }^{3,4748}$. Fue descrito inicialmente por Gammel, en 1952 en una paciente de 55 años con cáncer de mama, como una erupción del tronco y las extremidades, que se resolvió a las seis semanas de la mastectomía. Este autor describió la entidad como lesiones pruriginosas que simulaban las vetas de la corteza en la madera de un árbol ${ }^{49}$.

\section{Epidemiología}

Es una entidad poco frecuente que se presenta dos veces más en hombres que en mujeres y con un pico de edad a los 63 años, aunque puede presentarse a cualquier edad, y únicamente se ha descrito en pacientes caucásicos. Hasta el momento se han reportado, aproximadamente, 70 casos y se considera el síndrome paraneoplásico más específico ${ }^{48,50}$.

\section{Etiopatogenia}

La causa de esta entidad permanece desconocida. Según Gammel, las proteínas del tumor producen sustancias que son reconocidas como alérgenos ${ }^{49}$. Holt y Davies lograron demostrar depósitos de inmunoglobulina $\mathrm{G}$ y fracción del complemento 3 en la membrana basal de piel afectada y sana, lo que sugiere una causa inmunitaria. Los tres mecanismos patogénicos propuestos fueron:

1. reacción cruzada entre los antígenos del tumor y antígenos endógenos de piel;

2. alteración de antígenos de la piel debida a la acción de productos del tumor, que los hace propensos a una reacción autoinmunitaria y al depósito de complejos antígeno-anticuerpo, y

3. depósito en la piel de complejos inmunitarios ya formados provenientes de complejos antígeno-anticuerpo producidos por la reacción frente al tumor ${ }^{51}$.

También, se ha logrado demostrar anticuerpos antimembrana basal mediante inmunohistoquímica e inmunofluorescencia, en la membrana basal, en la piel adyacente y en el tumor primario ${ }^{52}$.

Los tumores con los que se ha encontrado relacionado el eritema gyratum repens son, en orden de frecuencia: pulmonar (32 a $40 \%$ ), gástrico y esofágico (8\%), mamario (6\%), vesical, uterino, de cuello uterino, prostático, anal, lingual, hipofaríngeo, mieloma múltiple y melanoma maligno ${ }^{48}$. Cabe destacar que en 4 a $6 \%$ de los casos se reportan causas no neoplásicas de eritema gyratum repens, entre ellas, tuberculosis, esclerodermia localizada, dermatosis ampollosas, síndrome de Sjögren y embarazo ${ }^{47}$. Incluso, se ha reportado en pacientes sanos ${ }^{3,53-58}$.

\section{Manifestaciones clínicas}

Se presenta como una dermatosis eritematosa serpiginosa. Puede manifestarse como una placa aislada o cientos de ellas y clínicamente se observan bandas anulares, concéntricas y eritematosas, que forman arcos y ondas que recuerdan las vetas de la madera o la piel de la cebra. Los bordes de las lesiones son eritematosos, en ocasiones pigmentados, bien definidos y descamativos, aunque generalmente no son palpables. Las lesiones se presentan, principalmente, en el tronco y las extremidades, respetando en la mayoría de casos las palmas, las plantas y la cara; crecen rápidamente, aumentando su tamaño hasta $1 \mathrm{~cm}$ al día (FIGURAS 3 Y 4). En $16 \%$ de los casos puede presentarse queratodermia palmoplantar, onicólisis e hiperqueratosis subungular ${ }^{3,47,48}$.

Generalmente, las lesiones se presentan un mes a seis años antes de las manifestaciones de la neoplasia, pero puede presentarse simultáneamente con el tumor o, incluso, nueve meses después de su diagnóstico ${ }^{59}$. 

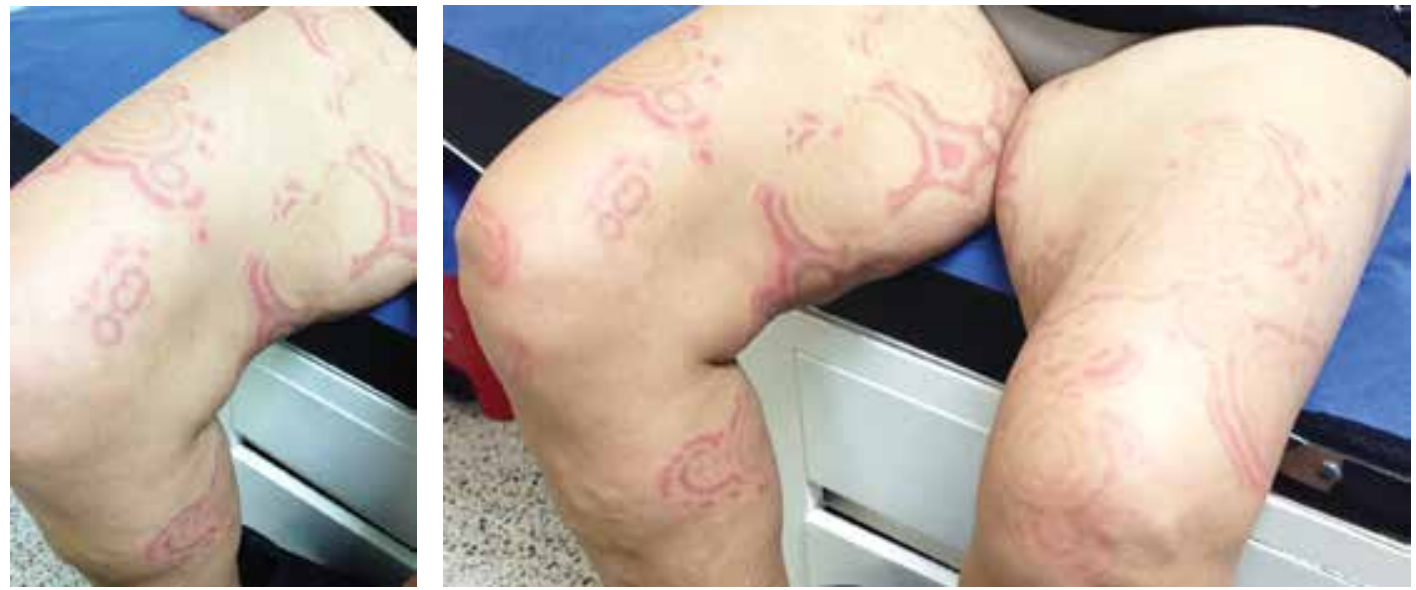

FIGURA 3 Y 4. Eritema gyratum repens en una paciente de 52 años. Hasta el momento no se ha encontrado neoplasia maligna en los estudios de extensión.

\section{Histopatología}

Las alteraciones histológicas son inespecíficas, observándose hiperqueratosis moderada, paraqueratosis $\mathrm{y}$ espongiosis. Puede haber acantosis, tapones foliculares y licuefacción de la capa basal; en la dermis superficial hay capilares dilatados, infiltrado linfohistiocítico perivascular y, en ocasiones, algunos eosinófilos. Puede encontrarse edema endotelial vascular y de la dermis papilar, con escasos melanófagos. La inmunofluorescencia directa revela depósitos granulares de IgG y $\mathrm{C}_{3}$ en la membrana basal de la piel afectada y la piel sana ${ }^{3,47,48}$.

\section{Diagnóstico diferencial}

Hay ciertas enfermedades que pueden adoptar características clínicas similares a las del eritema gyratum repens (TABLA 2) 3,58

\begin{tabular}{cc}
\hline \hline & \\
Eritema necrolítico migratorio & $\begin{array}{c}\text { Eritema anular centrí- } \\
\text { fugo }\end{array}$ \\
Eritema marginado & $\begin{array}{c}\text { Lupus eritematoso } \\
\text { subagudo }\end{array}$ \\
Eritroqueratodermia variable & Pitiriasis rubra pilaris \\
Psoriasis & Penfigoide ampolloso \\
Urticaria vasculítica & \\
\hline
\end{tabular}

TABLA 2. Diagnósticos diferenciales de eritema gyratum repens

\section{Tratamiento}

Es de gran importancia tener en cuenta esta entidad en un paciente con lesiones figuradas debido a su connotación paraneoplásica, ya que, en ocasiones, el tratamiento temprano de la neoplasia maligna subyacente depende de un diagnóstico oportuno. Por lo general, el tratamiento de la neoplasia visceral lleva a la involución de las lesiones, pero con la aparición de metástasis las lesiones en piel pueden recurrir. Se ha reportado el tratamiento con esteroides sistémicos, azatioprina y análogos de la vitamina A, con efectividad limitada ${ }^{48}$. La mortalidad de esta enfermedad se debe exclusivamente a la neoplasia maligna subyacente ${ }^{3,60}$.

\section{Eritema migrans}

El eritema migrans, también llamado eritema crónico migrans por Afzelius, quien hizo su descripción inicial en $1909^{61}$, es la manifestación inicial y característica de la enfermedad de Lyme, una enfermedad infecciosa con compromiso multisistémico que incluye la piel y otros órganos, como el sistema nervioso central, el musculo esquelético y el corazón. Es la enfermedad zoonótica más común en Europa y se origina por la picadura de garrapatas del género Ixodes ricinus, que se encuentren infectadas por bacterias de tipo espiroqueta del complejo Borrelia burgdorferi sensu lato. Aunque también se ha encontrado esta bacteria en fluidos de pulgas, moscas y mosquitos, no se ha demostrado la transmisión a humanos a partir de estos insectos ${ }^{62}$. Los principales reservorios de Ixodes son los roedores ${ }^{3,62}$. 


\section{Epidemiología}

Esta entidad se encuentra con mayor frecuencia en Europa y Estados Unidos, con una incidencia de 5,2 por cada 100.000 habitantes ${ }^{3}$. No tiene predilección según el sexo y, aunque puede aparecer a cualquier edad, se han reportado dos picos entre los 5 y los 9 años y entre los 55 y los 59 años de edad ${ }^{63}$. La mayoría de los casos se presentan en primavera, verano y otoño, cuando las picaduras son más frecuentes, debido al ciclo de vida de las garrapatas que se alimentan de sangre humana una vez por cada fase de su evolución (larva, ninfa y garrapata adulta) $)^{3,64}$.

\section{Etiopatogenia}

La espiroqueta se transfiere al humano si la garrapata permanece adherida entre 24 y 72 horas, para luego desprenderse de manera espontánea. Sólo entre 14 y $32 \%$ de los pacientes refieren el antecedente de picadura por el artrópodo, ya que en la mayoría de los casos no hay dolor (FIGURAS 5 Y 6) ${ }^{65}$. Tras su inoculación, la bacteria ingresa a la piel, generando la lesión característica, o migra hacia otros sitios, como el sistema nervioso central y las articulaciones, por vía hemática, linfática o $a b s^{62,63}$. Una vez que las lipoproteínas de las espiroquetas ingresan al torrente sanguíneo, pueden desencadenar una respuesta inmunitaria innata y adaptativa, estimulando la producción de citocinas por macrófagos y células $\mathrm{T}$ (Th1) ${ }^{3}$. El eritema migrans puede ser una reacción de hipersensibilidad a las proteínas de la saliva de la garrapata, en cuyo casos su aparición y desaparición son rápidas (horas a días)3.

\section{Manifestaciones clínicas}

La infección por B. burgdorferi puede comprometer diferentes órganos, entre los que se encuentran piel, corazón, articulaciones y sistema nervioso central como los más frecuentemente afectados ${ }^{62}$. La enfermedad tiene tres estadios clínicos que son infección temprana localizada, temprana diseminada y tardía persistente; no obstante, estos no se presentan siempre de manera secuencial, porque en ocasiones la enfermedad no se manifiesta sino hasta etapas muy avanzadas. Sólo se discutirá aquí la infección temprana localizada ${ }^{66}$.

El eritema migrans es el signo clínico dermatológico principal de la enfermedad de Lyme, el cual se presenta en 60 a $80 \%$ de los pacientes ${ }^{61}$. Se considera patognomónico de esta entidad, con un período de incubación que varía de 3 a 32 días, aunque hay reportes incluso de aparición tres meses después de la infección.

Se inicia en el sitio de la picadura, generalmente en los miembros inferiores (54\%) y el tronco (29\%), la cual frecuentemente pasa inadvertida ${ }^{62}$. Clínicamente, se inicia como una mácula pequeña no descamativa y eritematosa, que luego se convierte en pápula y se extiende centrífugamente hasta alcanzar los $5 \mathrm{~cm}$ con curación central, lo que le da un aspecto anular.

El diámetro del eritema migratorio puede ir de algunos milímetros hasta $20030 \mathrm{~cm}$ (promedio de 16 $\mathrm{cm})^{62,63}$, el cual es directamente proporcional a la duración de la infección, que en promedio es de 10 días, y

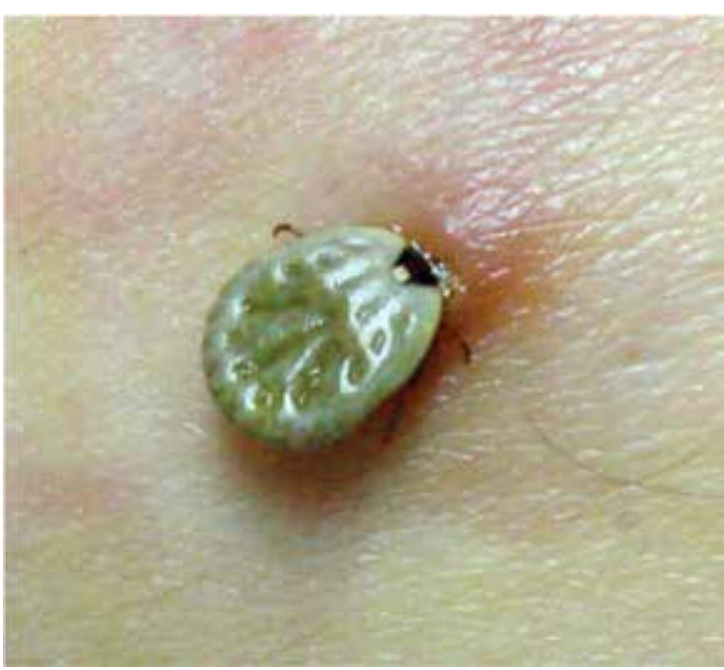

FIGURA 5. La garrapata se adhiere a la piel y pasa desapercibida por su tamaño.

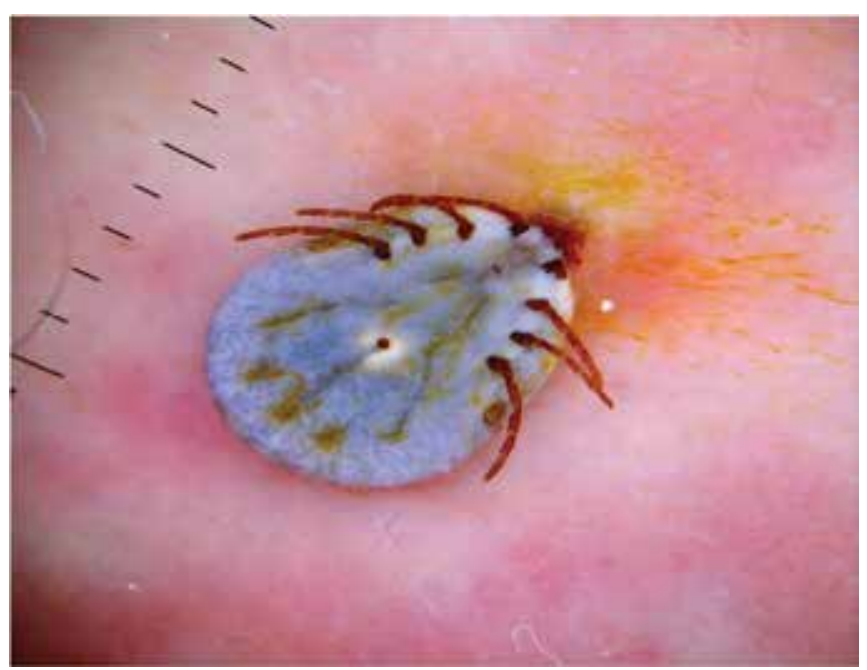

FIGURA 6. Vista dermatoscópica de la garrapata adherida a la piel. 
la banda de expansión periférica mide entre 0,5 y $1 \mathrm{~cm}$ de diámetro ${ }^{3,64}$. A pesar de que el eritema migrans es, por lo general, solitario, en 6 a $48 \%$ de los casos puede haber varias lesiones que representan la diseminación de la bacteria a otros sitios de piel $^{3}$.

Estas lesiones aparecen a los pocos días de la lesión inicial, pero son más pequeñas y con un centro más claro; pueden presentarse en cualquier sitio de la piel, exceptuando mucosas, palmas y plantas, y su número varía de 2 a 70 lesiones, con un promedio de 3 a 5 lesiones por persona ${ }^{3,64}$. Pueden presentarse también lesiones hemorrágicas, ampollosas, áreas descamativas o incluso, pequeñas máculas eritematosas, placas edematosas o ambas en el sitio de la picadura, las cuales pueden pasar inadvertidas ya que generalmente son asintomáticas 3,62,64.

Junto con estas lesiones puede presentarse malestar general, fatiga, artralgias, mialgias, cefalea, linfadenopatías y fiebre, pero no deben confundirse con manifestaciones extracutáneas de la infección ${ }^{64}$.

\section{Histopatología}

La epidermis se encuentra respetada y en la dermis se encuentra un infiltrado linfoplasmocitario perivascular superficial, profundo e intersticial. Pueden encontrarse frecuentemente eosinófilos y observarse espiroquetas en la epidermis y la dermis con la tinción de Warthin-Starry, en especial, si se toma la biopsia de la periferia de la lesión ${ }^{3,64,67}$.

\section{Diagnóstico}

Aunque en la mayoría de los casos el diagnóstico de esta entidad conlleva un reto para el médico, si se tienen en cuenta la evolución, los datos epidemiológicos y un adecuado análisis de los hallazgos clínicos e histológicos, el diagnóstico de la entidad no debe representar un problema, a menos que la presentación sea diseminada o atípica, para lo cual se debe hacer un interrogatorio muy preciso buscando el antecedente de exposición a picaduras de garrapatas y otros factores de riesgo $0^{3,62}$.

La serología en las etapas tempranas de la infección puede dar lugar a falsos negativos; además, la histopatología por sí sola y los títulos de anticuerpos séricos contra B. burgdorferi detectados mediante ELISA, tienen una gran probabilidad de falsos positivos por reacción cruzada con otros microorganismos, como el de la sífilis y el virus de Epstein-Barr, o enfermedades autoinmunitarias, por lo que estos resultados no son diagnósticos y una serología negativa tampoco descarta esta entidad ${ }^{64}$. Idealmente, el diagnóstico debe confirmarse por Western blot y cultivo de tejido ${ }^{62}$.
La respuesta humoral se inicia con anticuerpos IgM, que aparecen a las dos a cuatro semanas de la infección ${ }^{68}$; sus niveles pico se presentan entre las 8 y 10 semanas, para luego presentar disminución gradual. La inmunoglobulina G (IgG) puede persistir varios años y esta aparece en suero a las seis semanas de la infección, con niveles pico a los cuatro a seis meses ${ }^{62}$. Para la detección de ADN específico de $B$. burgdorferi, se ha utilizado también la reacción en cadena de la polimerasa (PCR), un método muy sensible y específico ya que detecta segmentos de la bacteria y segmentos compartidos por el grupo ${ }^{64}$. La biopsia de piel no se practica de rutina, aunque puede ser de gran utilidad, principalmente cuando se quiere descartar otras enfermedades $^{63}$.

\section{Diagnóstico diferencial}

Debe hacerse el diagnóstico diferencial con lesiones anulares que se asocien con síntomas generales, como erisipela, celulitis y otras entidades con patrón anular, tales como erupción fija por fármacos, dermatomiositis, lupus eritematoso cutáneo, reacciones a picaduras de insectos, esclerodermia localizada, tinea corporis, dermatitis de contacto, erytema gyratum repens y granuloma anular. Cuando hay lesiones múltiples, deben diferenciarse del síndrome de Sweet y el eritema multiforme ${ }^{3,64}$.

\section{Tratamiento}

Los antibióticos son el pilar del tratamiento en estos pacientes, ya que al eliminar la espiroqueta se previenen las complicaciones a largo plazo. Es muy importante destacar que la instauración del tratamiento antibiótico en las fases tempranas de la enfermedad, puede ayudar a curarla hasta en $99 \%$ de los pacientes; de lo contrario, la enfermedad puede diseminarse y afectar otros órganos.

El tratamiento de elección para la enfermedad de Lyme es la doxiciclina en dosis de $100 \mathrm{mg}$ por vía oral dos veces al día durante un período de 14 a 21 días en adultos y en la población pediátrica es de elección la amoxicilina, $50 \mathrm{mg} / \mathrm{kg}$ por día por el mismo período, ya que las tetraciclinas se encuentran contraindicadas $^{62,64}$. Otras alternativas son: amoxicilina, $500 \mathrm{mg}$ cada 8 horas, cefuroxime axetil, $500 \mathrm{mg}$ cada 12 horas, y azitromicina durante dos a tres semanas ${ }^{3,64}$. Pueden presentarse recurrencias ya que la infección no proporciona inmunidad de por vida y debe hacerse seguimiento clínico ya que con la serología no se logra hacer diagnósticos precisos ${ }^{63}$. 


\section{Eritema necrolítico migratorio}

El eritema necrolítico migratorio es una enfermedad dermatológica rara que se encuentra asociada con tumores pancreáticos neuroendocrinos y forma parte del síndrome de glucagonoma, una entidad que se presenta en pacientes con tumor de células alfa 2 del páncreas. Generalmente, el tumor se localiza en los islotes del cuerpo y la cola, aunque puede encontrarse en cualquier lugar del páncreas e, incluso, en el intestino delgado. Usualmente, el diagnóstico es tardío y las metástasis son frecuentes ${ }^{69}$.

Fue descrita por primera vez en 1942, por Becker, et al., en una mujer con pérdida de peso, anemia y tromboembolia, a quien se le diagnosticó un tumor de páncreas y aumento del glucagón sérico; además, presentaba una dermatitis necrótica vésico-eritematosa y estomatitis $^{69,70}$. Wilkinson propuso el nombre actual, en 1973.

\section{Epidemiología}

El eritema necrolítico migratorio se produce por un tumor del sistema neuroendocrino y es una manifestación rara, ya que sólo se encuentran sus lesiones en 1 de cada 20 a 200 millones de pacientes afectados por el tumor. Se presenta principalmente en la quinta a séptima décadas de la vida y sólo en un cuarto de los casos afecta menores de 40 años. Es más frecuente en mujeres, aunque algunos autores no han encontrado diferencias entre ambos sexos ${ }^{3,69,71}$.

El eritema necrolítico migratorio puede asociarse a otros procesos patológicos, como cirrosis hepática, enfermedad pancreática no tumoral como diabetes mellitus descompensada, insuficiencia renal crónica, síndrome de Cushing, enfermedad celíaca, hiperglucagonemia familiar, traumas, quemaduras o cirugías, bacteriemia; también, con el tratamiento con danazol, sin necesidad de encontrar aumento del glucagón sérico y, en estos casos, se denomina síndrome de seudoglucagonoma; sin embargo, se resalta que, aunque existen estas excepciones, el eritema necrolítico migratorio es el signo sine qua non del síndrome de glucagonoma ${ }^{69}$.

\section{Etiopatogenia}

La fisiopatología de los cambios en la piel permanece aún sin esclarecerse, ya que hasta la fecha no se ha comprobado que se relacionen con la producción de glucagón, aunque en algunas hipótesis se argumenta que la elevación de esta enzima puede contribuir en gran medida a la necrólisis epidérmica ${ }^{72}$. También, se postulan los déficits nutricionales de cinc, aminoácidos y

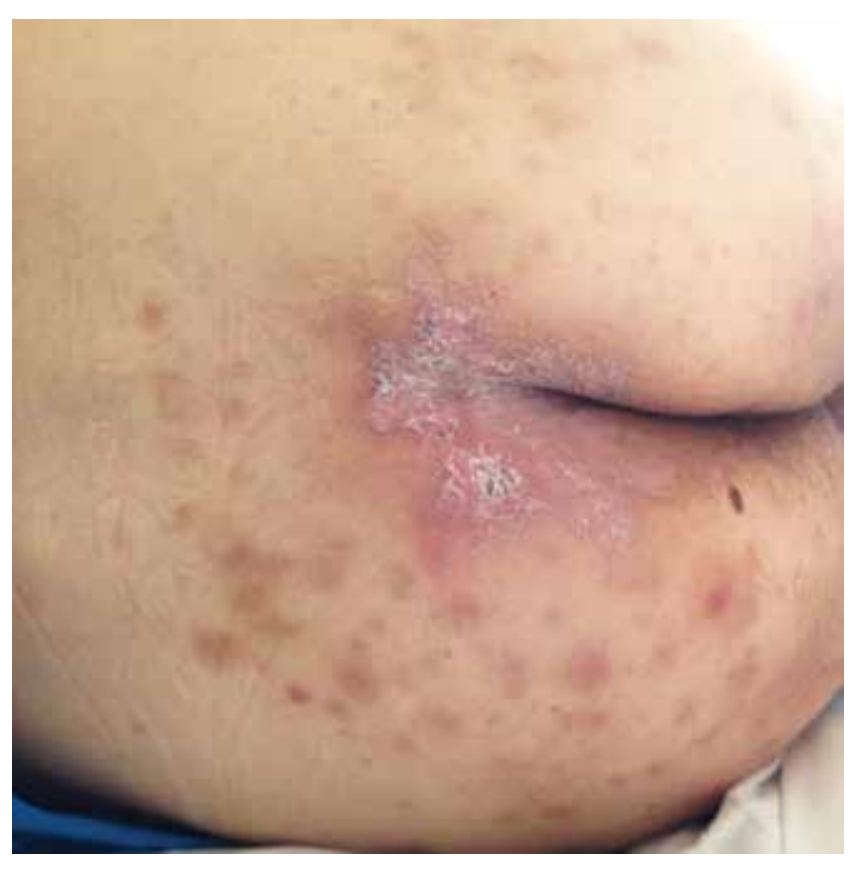

FIGURA 7. Eritema necrolítico migratorio: múltiples placas eritematosas y costras en la región interglútea.

algunos ácidos grasos como los factores más implicados en la fisiopatología de esta entidad ${ }^{3,72}$.

\section{Manifestaciones clínicas}

Esta entidad se presenta generalmente de manera recurrente, con aparición y desaparición espontánea de las lesiones, que pueden ser localizadas o generalizadas. Comienza con pápulas o máculas eritematosas que confluyen y posteriormente se diseminan; en el centro de las lesiones aparecen vesículas, pústulas, ampollas, erosiones y costras en un lapso de dos semanas. Finalmente, producen hiperpigmentación posinflamatoria, pero usualmente no dejan cicatriz. El mismo paciente puede presentar lesiones en diferentes etapas de evolución. Los sitios frecuentemente comprometidos son las zonas alrededor de los orificios de la cara y los pliegues, principalmente inguinales y perigenitales (FIGURA 7), y menos frecuentemente, tobillos, pies y pulpejos de los dedos. En la piel y las mucosas puede haber otras manifestaciones, como estomatitis, glositis, queilitis angular, distrofia de uñas y onicomadesis, y puede presentarse el fenómeno de Koebner ${ }^{69,71}$. La sobreinfección es común, en la mayoría de casos por Staphylococcus aureus y Candida albicans ${ }^{69}$.

Es de gran importancia cuando nos enfrentamos a un paciente con eritema necrolítico migratorio, tener en cuenta las manifestaciones sistémicas, como pérdida de peso, diabetes, diarrea, mala absorción, anemia, es- 
tomatitis, tromboembolia, y alteraciones gastrointestinales y neuropsiquiátricas ${ }^{73}$.

Otras enfermedades asociadas al eritema necrolítico migratorio son enfermedad celiaca, fibrosis quística, hepatitis y pancreatitis, entre otras. Se pueden encontrar también otros tumores, entre ellos, hepatocarcinoma, adenocarcinoma de yeyuno y carcinoma bronquial $^{72}$.

\section{Histopatología}

En esta entidad se observa principalmente necrosis focal o confluente de la epidermis superior, hiperplasia psoriasiforme, paraqueratosis, adelgazamiento de la capa granular y espongiosis; además, puede encontrarse un infiltrado linfocitario perivascular leve, pero todos estos hallazgos son inespecíficos y pueden presentarse en otras dermatosis carenciales ${ }^{73}$. También, puede haber necrosis de la epidermis superior, desprendimiento del estrato córneo y formación de hendiduras que dan 'aspecto en bandera'. Otros hallazgos menos frecuentes son hiperqueratosis, ortoqueratosis, cúmulos de neutrófilos, edema y acantosis con hiperplasia de células basales $3,69,74$.

\section{Diagnóstico}

Debe iniciarse con una evaluación muy cuidadosa del paciente, teniendo en cuenta la naturaleza intermitente y recurrente de las lesiones, la localización y sus características, y asociando estos hallazgos con la presencia de síntomas constitucionales. El tumor se busca mediante ecografía, tomografía computarizada, resonancia magnética y angiografía selectiva ${ }^{69}$. Recientemente, se está usando la gammagrafía selectiva con octreótido y somatostatina, como una herramienta diagnóstica. Se deben solicitar hemograma, velocidad de sedimentación globular, niveles de glucagón en ayunas,

$$
\begin{array}{cc}
\begin{array}{c}
\text { Necrolisis epidérmica tóxica } \\
\text { Psoriasis pustular generali- } \\
\text { zada }
\end{array} & \text { Eritema multiforme } \\
\text { Penfigoide ampolloso } & \text { Psoriasis vulgar } \\
\text { Dermatitis alérgica de contacto } & \text { Eccemas crónicos } \\
\text { Acrodermatitis enteropática } & \begin{array}{c}
\text { Déficit de ácidos } \\
\text { grasos esenciales }
\end{array} \\
\text { Pelagra } & \begin{array}{c}
\text { Dermatosis pustular } \\
\text { subcórnea }
\end{array}
\end{array}
$$

Eritema multiforme
Psoriasis vulgar
Pénfigo foliáceo
Eccemas crónicos
Déficit de ácidos
grasos esenciales
Dermatosis pustular
subcórnea

TABLA 3. Diagnósticos diferenciales del eritema necrolítico migratorio ${ }^{69,71}$ un adecuado perfil hormonal gastrointestinal (insulina, somatostatina, ACTH, péptido intestinal vasoactivo), glucemia en ayunas, serología para hepatitis $C$ y enzimas hepáticas ${ }^{69}$. Otros exámenes, como los niveles de cinc, el perfil de aminoácidos o la medición de ácidos grasos esenciales, pueden ayudar a descartar los demás diagnósticos ${ }^{75}$. El diagnóstico definitivo de esta entidad se hace evidenciando exceso de glucagón sérico en ayunas que, aunque el rango de aumento varía mucho entre uno y otro paciente, la mayoría de veces se encuentra por encima del valor normal (50 a $150 \mathrm{pg}$ por $\mathrm{ml}$ ) $69,71,72$.

En la TABLA 3 se presentan los diagnósticos diferenciales.

\section{Tratamiento}

El tratamiento del eritema necrolítico migratorio se divide en dos categorías: el de la condición subyacente y el sintomático. El tratamiento de la enfermedad de base se determina por la enfermedad tratada y su pronóstico depende del momento en el que se haga el diagnóstico, ya que cuando se encuentran metástasis el tratamiento es paliativo, y entre el 50 y el $100 \%$ de los pacientes se encuentran en esta fase de la enfermedad ${ }^{69,71}$. En $30 \%$ de los pacientes con eritema necrolítico migratorio, puede lograrse la resolución de los síntomas con la extirpación del tumor, pocos días después del procedimiento ${ }^{3}$.

Un adecuado enfoque consiste en combinar el tratamiento tópico y el sistémico. En el primero se incluyen los esteroides y preparados con cinc y alquitrán ${ }^{69}$. Entre los principales medicamentos para uso sistémico, el octreótido actúa regulando a la baja la conversión del glucagón en su forma activa, dando resultados en 48 a 72 horas y con resolución casi completa en dos semanas. Se han usado también esteroides orales, antibióticos, metotrexato y dapsona, y en otros estudios se ha demostrado beneficio con suplementos de cinc, ácidos grasos esenciales y aminoácidos, aunque se ha observado reaparición de las lesiones con la suspensión del tratamiento ${ }^{69,3}$.

Al igual que en otros tumores malignos, los pacientes con eritema necrolítico migratorio y glucagonoma tienen gran riesgo de enfermedad tromboembólica (30\%), la cual es la causa de muerte hasta en la mitad de los pacientes, por lo que requieren anticoagulación profiláctica a largo plazo con warfarina o heparinas de bajo peso molecular ${ }^{76-78}$.

\section{Conclusión}

Los eritemas figurados son entidades en ocasiones difíciles de reconocer, pero que constituyen enfermedades que el dermatólogo debe tener presente, ya que algunas tienen de base entidades que deben recibir tratamiento 
oportuno para evitar resultados desfavorables. Además, sus manifestaciones clínicas pueden preocupar al paciente y se debe tener conocimiento sobre sus causas para poder explicarlas.

\section{Agradecimientos}

A Carolina Velásquez por la fotografía 1, a Liliana Tamayo por la fotografía 2, a Juan Carlos Restrepo por las fotografías 3 y 4, y a Luz Marina Gómez por las fotografías 5 y 6.

\section{Referencias}

1. Goldsmith L, Katz S, Glichrest B, Paller A, Leffell D, Wolff K. Erithema annulare Centrifugum and other Figurate Erythemas. In: Katz S, editor. Fitzpatrick's Dermatology Gen. Med. United States of America; 2012. p. 463-6.

2. Martinón-Torres F. Eritema figurado “tipo profundo.”An Esp Pediatr. 2000;53:380-2.

3. Kaminsky A. Eritemas figurados. Actas Dermosifiliogr. 2009;100(2):88-109.

4. Bottoni U, Innocenzi D, Bonaccorsi P, Carlesimo M, Faina P, Richetta A, et al. Erythema annulare centrifugum: report of a case with neonatal onset. J Eur Acad Dermatol Veneorol. 2002;16(5):500-3.

5. Klaber R. Erythema Gyratum Perstans (Colcott Fox). Proc R Soc Med. 1942;36(2):45.

6. Ziemer M, Eisendle K, Zelger B. New concepts on erythema annulare centrifugum : a clinical reaction pattern that does not represent a specific clinicopathological entity. Br J Dermatol. 2009;160(1):119-26.

7. García M, Pujol R, Gimenez-Arnau A, Barranco C. Annually recurring erythema annulare centrifugum: a distinct entity? J Am Acad Dermatol. 2006;54(6):1091-5.

8. Darier J. De l'érythème annulaire centrifuge. Ann Dermatol Syphilogr. 1916;6:57.

9. Mahood JM. Erythema annulare centrifugum: a review of 24 cases with special reference to its association with underlying disease. Clin. Exp. Dermatol. 1983 Jul;8(4):383-7.

10. Enomoto H. Erythema annulare centrifugum as the presenting sign of breast carcinoma. Eur Acad Dermatol Venereol. 2009;23:317-68.

11. Chodkiewicz H, Cohen P. Paraneoplastic Erythema Annulare Centrifugum Eruption: PEACE. Am J Ciln Dermatol. 2012;13(4):239-46.

12. Reichel M, Wheeland R. Inflammatory carcinoma masquerading as erythema annulare centrifugum. Acta Derm Venereol. 1993;73(2):138-40.

13. Lee H, Chang S, Lee M, Choi J, Moon K, Koh J. Metastatic gastric carcinoma presenting as an erythema annulare centrifugum-like lesion. J Dermatol. 2008;35(3):186-7.

14. Helbing I, Walewska R, Dyer M, Bamford M, Harman K. Erythema annulare centrifugum associated with chronic lymphocytic leukaemia. Br J Dermatol. 2007;157(5):1044-5.
15. Yaniv R, Shpielberg O, Shpiro D, Feinstein A, Ben-Bassat I. Erythema annulare centrifugum as the presenting sign of Hodgkin's disease. Int J Dermatol. 1993;32(1):59-61.

16. Furue M, Akasu R, Ohtake N, Tamaki K. Erythema annulare centrifugum induced by molluscum contagiosum. Br J Dermatol. 1993;129(5):646-7.

17. Borbujo J, de Miguel C, Lopez A, de Lucas R, Casado M. Erythema annulare centrifugum and Escherichia coli urinary infection. Lancet. 1996;347(9005):897-8.

18. Hammar H. Erythema annulare centrifugum coincident with Epstein-Barr virus infection in an infant. Acta Paediatr Scand. 1974;63(5):788-92.

19. Jillson O. Allergic confirmation that some cases of erythema annulare centrifugum are dermatophytides. AMA Arch Derm Syphilol. 1954;70(3):355-9.

20. Burkhart C. Erythema annulare centrifugum. A case due to tuberculosis. Int J Dermatol. 1982;21(9):538-9.

21. Hendricks A, Lu C, Elfenbein G, Hussain R. Erythema Annulare Centrifugum Associated With Ascariasis. Arch Dermatol. 1981;117(9):582-5.

22. Betlloch I, Amador C, Chiner E, Varona C, Carbonell C, Vilar A. Erythema annulare centrifugum in Q fever. Int J Dermatol. 1991;30(7):502.

23. Shelley W. Erythema annulare centrifugum due to candida albicans. Br J Dermatol. 1965;77:383-4.

24. Goette D, Beatrice E. Erythema annulare centrifugum caused by hydrochlorothiazide-induced interstitial nephritis. Int J Dermatol. 1988;27:129-30.

25. Hogan D, Blocka K. Erythema annulare centrifugum associated with piroxicam. J Am Acad Dermatol. 1985;13(5 pt 1):840-1.

26. Garcia-Doval I, Peteiro C, Toribio J. Amitriptyline-induced erythema annulare centrifugum. Cutis. 1999;63(1):35-6.

27. Tsuji T, Nishimura M, Kimura S. Erythema annulare centrifugum associated with gold sodium thiomalate therapy. J Am Acad Dermatol. 1992;27(2 pt2):284-7.

28. Hudson L. Erythema annulare centrifugum: an unusual case due to hydroxychloroquine sulfate. Cutis. 1985;36(2):129-30.

29. Ashurst P. Erythema annulare centrifugum due to hydroxychloroquine sulfate and chloroquine sulfate. Arch Dermatol. 1967;95(1):37-9.

30. Merrett A, Marks R, Dudley F. Cimetidine-induced erythema annulare centrifugum: no cross-sensitivity with ranitidine. Br Med J. 1981;283:698.

31. Carsuzaa F, Pierre C. 'Erythe `me annulaire centrifuge al'aldactone. Ann Dermatol Venereol. 1987;114:375-6.

32. Weyers W, Díaz C, Weyers I. Erythema Annulare Centrifugum Results of a Clinicopathologic Study of 73 Patients. Am J Dermatopathol. 2003;25(6):451-62.

33. Braunstein B. Erythema annulare centrifugum and Graves ${ }^{\prime}$ disease. Arch Dermatol. 1982;118(9):623.

34. Altomare G, Capella G, Frigerio E. Sarcoidosis presenting as erythema annulare centrifugum. Clin Exp Dermatol. 1995;20(6):502-3.

35. Dippel E, Orfanos C, Zouboulis C. Linear IgA dermatosis presenting with erythema annulare centrifugum lesions: report of three cases in adults. J Eur Acad Dermatol Veneorol. 2001;15(2):167-70. 
36. Tsuji T, Kadoya A. Erythema annulare centrifugum associated with liver disease. Arch Dermatol. 1986;122(11):1239-40.

37. Thami G, Sachdeva A, Kaur S, Mohan H, Kanwar A. Erythema annulare centrifugum following pancreatico-biliary surgery. J Dermatol. 2002;29(6):347-9.

38. Ibrahim S, Pryor J, Tausk F. Stress-induced erythema annulare centrifugum. Dermatol Online J. 2009;15(4):15.

39. Choonhakarn C, Seramethakun P. Erythema annulare centrifugum associated with pregnancy. Acta Derm Venereol. 1998;78(3):237-8.

40. Dogan G. Pregnancy as a Possible Etioiogic Factor in Erythema Annulare Centrifugum. Am J Clin Dermatol. 2009;10(1):33-5.

41. Rosina P, D’Onghia F, Barba A. Erythema annulare centrifugum and pregnancy. Int J Dermatol. 2002;41(8):516-7.

42. Kuhn A, Richter-Hintz D, Oslislo C, Ruzicka T, Megahed M, Lehmann P. Lupus erythematosus tumidus. A neglected subset of cutaneous lupus erythematosus: report of 40 cases. Arch Dermatol. 2000;136(8):1033-41.

43. Ruiz H, Sánchez J. Tumid lupus erythematosus. Am J Dermatopathol. 1999;21(4):356-60.

44. Gniadecki R. Calcipotriol for erythema annulare centrifugum. Br J Dermatol. 2002;146(2):317-9.

45. Rao N, Pariser R. Annular erythema responding to tacrolimus ointment. J Drugs Dermatol. 2003;2(4):421-4.

46. Minni J, Sarro R. A novel therapeutic approach to erythema annulare centrifugum. J Am Acad Dermatol. 2006;54(3 spt 2):134-5.

47. De La Torre-Lugo E, Sánchez J. Erythema gyratum repens. J Am Acad Dermatol. 2011;64(5):89-90.

48. Eubanks L, Mcburney E, Reed R. Erythema Gyratum Repens. Am J Med Sci. 2001;321(5):302-5.

49. Gammel J. Erythema gyratum repens; skin manifestations in patient with carcinoma of breast. AMA Arch Derm Syphilol. 1952;66(4):494-505.

50. Boyd A, Neldner K, Menter A. Erythema gyratum repens: a paraneoplastic eruption. J Am Acad Dermatol. 1992;26(5 pt 1):757-62.

51. Holt P, Davies M. Erythema gyratum repens-an immunologically mediated dermatosis? Br J Dermatol. 1977;96(4):343-7.

52. Caux F, Lebbe C, Thomine E, Benyahia B, Flageul B, Joly P, et al. Erythema Gyratum Repens. A Case Studied With Immunofluorescence, Immunoelectron Microscopy And Immunohistochemistry. Br J Dermatol. 1994;131(1):102-7.

53. Bryan M, Lienhart K, Smoller B, Johnson S. Erythema gyratum repens in a case of resolving psoriasis. J Drugs Dermatol. 2003;2(3):315-7.

54. Kawakami T, Saito R. Erythema Gyratum Repens Unassociated With Underlying Malignancy. J Dermatol. 1995;22(8):587-9.

55. Reynoso C, Balderrama C, Martinez E, Tinoco E, Rodriguez E. Bullous pemphigoid with figurate erythema. A case report. Rev Med Inst Mex Seguro Soc. 2008;46(4):427-30.

56. Dermitsu T, Sasaki K, Iida E, Azuma R, Umemoto N, Kakurai M, et al. Urticarial Vasculitis Presenting as Erythema Gyratum RepensLike Eruption. J Eur Acad Dermatol Venereol. 2009;23(2):215-7.

57. Yebra I, Garcia B, Camacho F. Eritema gyratum repens de Gammel y enfermedad de Hodgkin. Med Cutan Ibero Lat Am. 1983;11(4):281-6.
58. Kreft B, Marsch W. Lupus erythematosus gyratus repens. Eur J Dermatol. 2007;17(1):79-82.

59. Harrison P. The annular erythemas. Int J Dermatol. 1979;18(4):282-90.

6o. Appell M, Ward W, Tyring S. Erythema gyratum repens. A cutaneous marker of malignancy. Cancer. 1988;62(3):548-50.

61. Steere A, Bartenhagen N, Craft J, Hutchinson G, Newman J, Rahn $\mathrm{D}$, et al. The early clinical manifestations of Lyme disease. Ann Intern Med. 1983;99:76-82.

62. Biesiada G, Czepiel J, Leśniak M, Garlicki A, Mach T. Lyme disease: review. Arch Med Sci. 2012;8(6):978-82.

63. Wright WF, Riedel DJ, Talwani R, GilliamBL. Diagnosis and Management of Lyme Disease. Am Fam Physician. American Family Physician; 2012;85(11):1086-93.

64. Müllegger R, Glatz M. Skin manifestations of lyme borreliosis: diagnosis and management. Am J Clin Dermatol. 2008;9(6):355-68.

65. Burgdorfer W, Barbour A, Hayes S, Benach J, Grunwaldt E, Davis J. Lyme disease-a tick-borne spirochetosis? Science (80-. ). 1982;216(4552):1317-9.

66. Asbrink E, Hovmark A. Early and late cutaneous manifestations in Ixodes-borne borreliosis. Ann NY Acad Sci. 1988;539:4-15.

67. Mullegger R, Mchugh G, Ruthazer R, Binder B, Kerl H, Steere A. Differential expression of cytokine mRNA in skin specimens from patients with erythema migrans or acrodermatitis chronica atrophicans. J Invest Dermatol. 2000;115:1115-1123.

68. Schoen R. Better Laboratory Testing for Lyme Disease : No More Western Blot. Clin Infect Dis. 2013;57(3):341-3.

69. Adam D, Cohen P, Ghazarian D. Necrolytic Migratory Erythema:Case Report and Clinical Review. J Cutan Med Surg. 2003;7(4):333-8.

70. Mallinson C, Bloom S, Warin A, Salmon P, Cox B. A glucagonoma syndrome. Lancet. 1974;2(7871):1-5.

71. Van Beek A, de Haas E, van Vloten W, Lips C, Roijers J, Canningavan Dijk M. The glucagonoma syndrome and necrolytic migratory erythema: a clinical review. Eur J Endocrinol. 2004;151(5):531-7.

72. Tierney E BJ. Etiology and Pathogenesis of Necrolytic Migratory Erythema: Review of the Literature. MedGenMed. 2004;6(3):1-13.

73. Grewal P, Salopek T. Is Necrolytic Migratory Erythema Due to Glucagonoma a Misnomer? A More Apt Name Might Be Mucosal and Intertriginous Erosive Dermatitis. J Cutan Med Surg. 2012;16(2):76-82.

74. Binnick A, Spencer S, Dennison W, Horton E. Glucagonoma syndrome. Report of two cases and literature review. Arch Dermatol. 1977;113(6):749-54.

75. Mendoza-Guil F, Hernandez-Jurado I, Burkhardt P, Linares J, Naranjo R. [Necrolytic migratory erythema associated with glucagonoma]. Actas Dermosifiliogr. 2005;96(3):175-8.

76. Burton J. Zinc and essential fatty acid therapy for necrolytic migratory erythema. Arch Dermatol. 1993;129(2):246.

77. Blackford S, Wright S, Roberts D. Necrolytic migratory erythema without glucagonoma: the role of dietary essential fatty acids. $\mathrm{Br}$ J Dermatol. 1991;125(5):460-46.

78. Smith A, Doolas A, Staren E. Rapid resolution of necrolytic migratory erythema after glucagonoma resection. J Surg Oncol. 1996;61(4):306-9. 